\title{
Isorhamnetin alleviates lipopolysaccharide-induced inflammatory responses in BV2 microglia by inactivating NF-кB, blocking the TLR4 pathway and reducing ROS generation
}

\author{
SHIN YOUNG KIM ${ }^{1}$, CHENG-YUN JIN ${ }^{2}$, CHEOL HONG KIM ${ }^{1}$, YOUNG HYUN YOO ${ }^{3}$, SUNG HYUN CHOI ${ }^{4}$, \\ GI-YOUNG KIM ${ }^{5}$, HYUN MIN YOON ${ }^{1}$, HWAN TAE PARK ${ }^{6}$ and YUNG HYUN $\mathrm{CHOI}^{7,8}$ \\ ${ }^{1}$ Department of Acupuncture and Moxibustion, Dongeui University College of Korean Medicine, Busan 47227, \\ Republic of Korea; ${ }^{2}$ School of Pharmaceutical Sciences, Institute of Drug Discovery and Development, \\ Zhengzhou University, Zhengzhou, Henan 450001, P.R. China; ${ }^{3}$ Department of Anatomy and Cell Biology, \\ Mitochondria Hub Regulation Center, College of Medicine, Dong-A University, Busan 49201; \\ ${ }^{4}$ Department of System Management, Korea Lift College, Geochang, South Gyeongsang 50141; \\ ${ }^{5}$ Department of Marine Life Sciences, School of Marine Biomedical Sciences, Jeju National University, Jeju 63243; \\ ${ }^{6}$ Department of Physiology, Peripheral Neuropathy Research Center, College of Medicine, \\ Dong-A University, Busan 49201; 7 Department of Biochemistry, Dongeui University College of Korean Medicine, \\ Busan 47227; ${ }^{8}$ Anti-Aging Research Center, Dongeui University, Busan 47340, Republic of Korea
}

Received July 3, 2018; Accepted November 9, 2018

DOI: $10.3892 /$ ijmm.2018.3993

\begin{abstract}
Isorhamnetin, which is a flavonoid predominantly found in fruits and leaves of various plants, including Hippophae rhamnoides L. and Oenanthe javanica (Blume) $\mathrm{DC}$, is known to possess various pharmacological effects. However, the anti-inflammatory potential of isorhamnetin remains poorly studied. Therefore, the present study aimed to investigate the inhibitory potential of isorhamnetin against inflammatory responses in lipopolysaccharide (LPS)-stimulated BV2 microglia. To measure the effects of isorhamnetin on inflammatory mediators and cytokines, and reactive oxygen species (ROS) generation, the following methods were used: cell viability assay, griess assay, ELISA, reverse transcriptase-polymerase chain reaction, flow cytometry, western blotting and immunofluorescence staining. The results revealed that isorhamnetin significantly suppressed LPS-induced secretion of pro-inflammatory mediators, including nitric oxide (NO) and prostaglandin $\mathrm{E}_{2}$,
\end{abstract}

Correspondence to: Dr Hwan Tae Park, Department of Physiology, Peripheral Neuropathy Research Center, College of Medicine, Dong-A University, 32 Daesingongwon-ro, Busan 49201, Republic of Korea

E-mail: phwantae@dau.ac.kr

Dr Yung Hyun Choi, Department of Biochemistry, Dongeui University College of Korean Medicine, 62 Yangjeong-ro, Busan 47227, Republic of Korea

E-mail: choiyh@deu.ac.kr

Key words: isorhamnetin, anti-inflammatory effects, nuclear factor- $\kappa \mathrm{B}$, Toll-like receptor 4 , reactive oxygen species without exhibiting significant cytotoxicity. Consistent with these results, isorhamnetin inhibited LPS-stimulated expression of regulatory enzymes, including inducible NO synthase and cyclooxygenase- 2 in BV2 cells. Isorhamnetin also downregulated LPS-induced production and expression of pro-inflammatory cytokines, such as tumor necrosis factor- $\alpha$ and interleukin-1 $\beta$. The mechanism underlying the anti-inflammatory effects of isorhamnetin was subsequently evaluated; this flavonoid inhibited the nuclear factor (NF) $-\kappa B$ signaling pathway by disrupting degradation and phosphorylation of inhibitor $\kappa \mathrm{B}-\alpha$ in the cytoplasm and blocking translocation of $\mathrm{NF}-\kappa \mathrm{B}$ p65 into the nucleus. In addition, isorhamnetin effectively suppressed LPS-induced expression of Toll-like receptor 4 (TLR4) and myeloid differentiation factor 88. It also suppressed the binding of LPS with TLR4 in BV2 cells. Furthermore, isorhamnetin markedly reduced LPS-induced generation of ROS in BV2 cells, thus indicating a strong antioxidative effect. Collectively, these results suggested that isorhamnetin may suppress LPS-mediated inflammatory action in BV2 microglia through inactivating the $N F-\kappa B$ signaling pathway, antagonizing TLR4 and eliminating ROS accumulation. Further studies are required to fully understand the anti-inflammatory effects associated with the antioxidant capacity of isorhamnetin; however, the findings of the present study suggested that isorhamnetin may have potential benefits in inhibiting the onset and treatment of neuroinflammatory diseases.

\section{Introduction}

Microglia function as macrophages in the central nervous system (CNS), and serve critical roles in brain development and maintenance. Microglial dysfunction caused by hyperac- 
tivity in response to inflammatory signals is closely associated with the onset and progression of various neurodegenerative diseases by damaging brain neurons $(1,2)$. Pathogenic endotoxins, including lipopolysaccharide (LPS), which are present in the outer membrane of Gram-negative bacteria, can induce excessive activation of microglial cells through binding to Toll-like receptor 4 (TLR4) $(3,4)$. TLR4 ultimately activates various downstream signal transduction pathways, including the nuclear factor (NF) $\kappa \mathrm{B}$ signaling pathway, thus leading to transcription of a series of pro-inflammatory genes that induce neuroinflammation and neurodegeneration (5-7). Overactivated microglial cells stimulated by LPS can induce oxidative stress by increasing the generation of reactive oxygen species (ROS), which further aggravates the inflammatory response $(8,9)$. Therefore, blocking excessive activation of microglia is an important tool to delay the induction and progression of numerous brain diseases.

Recent studies have reported that various natural products, including flavonoids, which are a group of naturally occurring polyphenol compounds found in plants, possess anti-inflammatory effects by blocking the activation of microglial cells (10-13). Isorhamnetin is a flavonoid present in various plants, including Hippophae rhamnoides L. (sea buckthorn) fruit and Oenanthe javanica (Blume) DC (water dropwort) leaf, which has been reported to possess various pharmacological effects. Previous studies have demonstrated that isorhamnetin can protect against inflammatory and oxidative stress responses in various in vitro and in vivo models using LPS, inflammatory cytokines and ischemic injury (14-24). The anti-inflammatory effects of isorhamnetin have been reported to be associated with inhibition of $\mathrm{NF}-\kappa \mathrm{B}$ signaling activity (20,23,25-27). In addition, its antioxidant effects can be achieved by blocking ROS production $(15,21,22)$. However, the association between TLRs and the anti-inflammatory action of isorhamnetin has yet to be elucidated. Furthermore, to the best of our knowledge, studies on the effects of isorhamnetin on microglia have also yet to be conducted. Therefore, the present study aimed to examine the anti-inflammatory and antioxidant potency of isorhamnetin, and to determine the effects of isorhamnetin on activation of the TLR4 signaling pathway in LPS-stimulated BV2 microglia.

\section{Materials and methods}

Cell culture and LPS stimulation. The BV2 immortalized murine microglial cell line was provided by Dr Il-Whan Choi (Department of Microbiology, College of Medicine, Inje University, Busan, Korea). BV2 microglia were maintained in Dulbecco's modified Eagle's medium (DMEM; WelGENE, Inc., Gyeongsan, Korea) containing $10 \%$ (v/v) fetal bovine serum (WelGENE, Inc.), L-glutamine (2 mM), penicillin (100 U/ml) and $100 \mu \mathrm{g} / \mathrm{ml}$ streptomycin (WelGENE, Inc.) at $37^{\circ} \mathrm{C}$ in a humidified atmosphere containing $5 \% \mathrm{CO}_{2}$ and $95 \%$ air. Isorhamnetin (Sigma-Aldrich; Merck KGaA, Darmstadt, Germany) was dissolved in dimethyl sulfoxide (DMSO; Sigma-Aldrich; Merck KGaA) and was adjusted to final concentrations using complete culture medium. The final DMSO concentration was $<0.05 \%$ in all experiments (i.e., a non-cytotoxic range). To stimulate cells, the medium was replaced with fresh DMEM and $100 \mathrm{ng} / \mathrm{ml}$ LPS (Sigma-Aldrich
Chemical Co.) was added in the presence or absence of isorhamnetin for the indicated time periods.

Assessment of cell viability. Cell viability was measured based on the formation of blue formazan, which is metabolized from colorless MTT by mitochondrial dehydrogenases, enzymes that are only active in live cells. Briefly, BV2 cells were seeded into 96-well plates at a density of $1 \times 10^{4}$ cells/well. After $24 \mathrm{~h}$ of incubation, cells were treated with various concentrations $(0,50,100$ and $200 \mu \mathrm{M})$ of isorhamnetin for $24 \mathrm{~h}$, or were pretreated with various concentrations of isorhamnetin for $1 \mathrm{~h}$ prior to LPS $(100 \mathrm{ng} / \mathrm{ml})$ treatment for $24 \mathrm{~h}$ at $37^{\circ} \mathrm{C}$. Subsequently, the medium was removed and MTT $(0.5 \mathrm{mg} / \mathrm{ml}$; Sigma-Aldrich; Merck KGaA) was added to each well. After $3 \mathrm{~h}$ at $37^{\circ} \mathrm{C}$, the supernatant was replaced with DMSO to dissolve blue formazan crystals in each well. After $10 \mathrm{~min}$ at $37^{\circ} \mathrm{C}$, optical density was measured at a wavelength of $540 \mathrm{~nm}$ using an ELISA microplate reader (Dynex Technologies, Chantilly, VA, USA). Growth inhibition was assessed as percentage viability where vehicle $(0.05 \%$ DMSO)-treated cells were taken as $100 \%$ viable (28).

Measurement of pro-inflammatory mediators and cytokines. Levels of nitric oxide (NO) production were indirectly determined by measuring the stable NO catabolite, nitrite, in the medium using the Griess reaction. Briefly, BV2 cells $\left(5 \times 10^{5}\right.$ cells $\left./ \mathrm{ml}\right)$ were stimulated in 24 -well plates with or without various concentrations of isorhamnetin for $1 \mathrm{~h}$ prior to LPS $(100 \mathrm{ng} / \mathrm{ml})$ treatment for $24 \mathrm{~h}$. Subsequently, the culture medium supernatant $(100 \mu \mathrm{l})$ was mixed with the same volume of Griess reagent (Sigma-Aldrich; Merck KGaA) and was incubated at room temperature for $10 \mathrm{~min}$. The optical density was then measured at $540 \mathrm{~nm}$ using an ELISA microplate reader; the concentration of nitrite was calculated according to a standard curve generated from known concentrations of sodium nitrite. Levels of prostaglandin $\mathrm{E}_{2}\left(\mathrm{PGE}_{2}\right)$ (cat. no. 514010; Cayman Chemical Company, Ann Arbor, MI, USA), tumor necrosis factor (TNF)- $\alpha$ (cat. no. MTA00B; R\&D Systems, Inc., Minneapolis, MN, USA), and interleukin (IL)-1 $\beta$ (cat. no. MLB00C; R\&D Systems, Inc.) in the culture medium were measured using commercial ELISA kits according to the manufacturer's protocols and as described previously (10). Briefly, cells were plated in 24 -well plates $\left(1.5 \times 10^{5}\right.$ cells/well $)$ and pretreated with various concentrations of isorhamnetin for $1 \mathrm{~h}$ prior to treatment with $100 \mathrm{ng} / \mathrm{ml} \mathrm{LPS} \mathrm{for} 24 \mathrm{~h}$. A $100-\mathrm{ml}$ aliquot of the conditioned medium was collected to determine $\mathrm{PGE}_{2}, \mathrm{TNF}-\alpha$ and IL- $1 \beta$ concentrations by ELISA, according to the recommended procedures. The cells were also treated with ISO $(200 \mu \mathrm{M})$ alone or in combination with $15 \mu \mathrm{M}$ ethyl-(6R)-6-(N-(2-chloro-4-fluorophenyl)sulfamoyl) cyclohex-1-ene-1-carboxylate (CLI-095; Invivogen Europe, Toulouse, France), a TLR4 antagonist, for $1 \mathrm{~h}$ prior to treatment with LPS for $24 \mathrm{~h}$.

RNA isolation and reverse transcription-polymerase chain reaction $(R T-P C R)$. BV2 cells were pretreated with various concentrations of isorhamnetin for $1 \mathrm{~h}$, followed by treatment with $100 \mathrm{ng} / \mathrm{ml}$ LPS for $24 \mathrm{~h}$. Total RNA was isolated from the cells using TRIzol ${ }^{\circledR}$ reagent (Invitrogen; Thermo Fisher Scientific, Inc., Waltham, MA, USA), according to the manu- 
facturer's protocol, and RNA levels were quantified. For mRNA expression analysis, cDNA was synthesized from $1 \mu \mathrm{g}$ total RNA using AccuPower ${ }^{\circledR}$ RT PreMix (Bioneer Corporation, Daejeon, Korea) containing Moloney murine leukemia virus reverse transcriptase, according to the manufacturer's protocol. The PCR reactions were performed using AccuPower ${ }^{\circledR}$ PCR PreMix (Bioneer Corporation) at $94^{\circ} \mathrm{C}$ for $5 \mathrm{~min}$, followed by 27 cycles at $94^{\circ} \mathrm{C}$ for $30 \mathrm{sec}$, annealing [inducible nitric oxide synthase (iNOS), $52^{\circ} \mathrm{C}$; cyclooxygenase (COX)-2, $57^{\circ} \mathrm{C}$; TNF- $\alpha, 57^{\circ} \mathrm{C}$; IL- $1 \beta, 57^{\circ} \mathrm{C}$; and GAPDH, $62^{\circ} \mathrm{C}$ ] for $30 \mathrm{sec}$ and $72^{\circ} \mathrm{C}$ for $30 \mathrm{sec}$, followed by a final extension step at $72^{\circ} \mathrm{C}$ for $5 \mathrm{~min}$. After amplification, the PCR products were separated by $1 \%$ agarose gel electrophoresis and were visualized using ethidium bromide (Sigma-Aldrich; Merck KGaA) staining. GAPDH was used as an internal control. Bands were semi-quantified using ImageJ (version 1.46; National Institutes of Health, Bethesda, MD, USA), were normalized to GAPDH and the ratio was determined. The PCR primers were as follows: iNOS forward, 5'-ATGTCCGAAGCAAACATCAC-3' and reverse, 5'-TAA TGTCCAGGAAGTAGGTG-3'; COX-2 forward, 5'-CAGC AAATCCTTGCTGTTCC-3' and reverse, 5'-TGGGCAAAG AATGCAAACATC-3'; TNF- $\alpha$ forward, 5'-TCTCATCAGTT CTATGGCCC-3' and reverse, 5'-GGGAGTAGACAA GGTACAAC-3'; IL-1 $\beta$ forward, 5'-GGGCTGCTTCCAAA CCTTTG-3' and reverse, 5'-GCTTGGGATCCACACTC TCC-3', and GAPDH forward, 5'-AGGCCGGTGCTGAGTA TGTC-3' and reverse, 5'-TGCCT GCTTCACCACCTTCT-3'.

Protein isolation and western blot analysis. BV2 cells were pretreated with various concentrations of isorhamnetin for $1 \mathrm{~h}$, followed by treatment with $100 \mathrm{ng} / \mathrm{ml}$ LPS for $24 \mathrm{~h}$. Alternatively, cells were treated with $100 \mathrm{ng} / \mathrm{ml}$ LPS for various durations. The cells were collected and cellular proteins were prepared using lysis buffer $[25 \mathrm{mM}$ Tris- $\mathrm{Cl}$ (pH 7.5), $250 \mathrm{mM} \mathrm{NaCl}, 5 \mathrm{mM}$ ethylenediaminetetraacetic acid (EDTA), 1\% Nonidet-P40, $1 \mathrm{mM}$ phenylmethylsulfonyl fluoride and $5 \mathrm{mM}$ dithiothreitol], as described previously (29). Cytosolic and nuclear proteins were isolated separately using an NE-PER Nuclear and Cytoplasmic Extraction Reagents kit (Pierce; Thermo Fisher Scientific, Inc.), according to the manufacturer's protocol. The insoluble materials were discarded by centrifugation at $13,000 \mathrm{x}$ g for $20 \mathrm{~min}$ at $4^{\circ} \mathrm{C}$. The protein concentrations in the cell lysates were determined using a detergent-compatible protein assay (Bio-Rad Laboratories, Inc., Hercules, CA, USA), according to the manufacturer's protocol. For western blotting, equal amounts of protein $(50 \mu \mathrm{g})$ were separated by $8-10 \%$ SDS-PAGE and were transferred onto polyvinylidene difluoride membranes (Schleicher and Schuell Bioscience, Inc., Keene, NH, USA). Subsequently, these membranes were blocked with 5\% non-fat dry milk/Tris-buffered saline containing $0.1 \%$ Triton X-100 (TBST) for $1 \mathrm{~h}$ at $25^{\circ} \mathrm{C}$ (room temperature) and were incubated with specific primary antibodies (Table I) at $4^{\circ} \mathrm{C}$ overnight. After washing membranes with TBST, they were incubated with appropriate horseradish-peroxidase (HRP)-conjugated secondary antibodies [1:500; cat. no. sc 2004, goat anti-rabbit immunoglobulin (Ig)G-HRP; sc 2005, goat anti-mouse IgG-HRP; Santa Cruz Biotechnology, Inc., Dallas, TX, USA] for $2 \mathrm{~h}$ at $25^{\circ} \mathrm{C}$. Protein bands were detected using an enhanced chemiluminescence kit (GE Healthcare, Chicago, IL, USA), according to the manufacturer's protocol. The immunoreactive bands were detected and exposed to X-ray film. Images of western blotting were also analyzed using ImageJ.

Immunofluorescence staining for nuclear translocation of $N F-\kappa B$ and formation of LPS/TLR4 complexes. After cells $\left(5 \times 10^{5}\right.$ cells $\left./ \mathrm{ml}\right)$ were pretreated with or without $200 \mu \mathrm{M}$ isorhamnetin for $1 \mathrm{~h}$, they were treated with $100 \mathrm{ng} / \mathrm{ml}$ LPS for $1 \mathrm{~h}$. The cells were then washed twice with PBS, fixed in $3.7 \%$ paraformaldehyde for $15 \mathrm{~min}$ at $25^{\circ} \mathrm{C}$, permeabilized with $0.2 \%$ Triton X-100 in PBS for 15 min, and blocked for 10 min at $20^{\circ} \mathrm{C}$ with PBS containing $5 \%$ bovine serum albumin (Sigma-Aldrich; Merck KGaA). The cells were then incubated with a primary antibody against NF- $\mathrm{KB}$ p65 (dilution, 1:100; cat. no. sc-71675; Santa Cruz Biotechnology, Inc.) at $4^{\circ} \mathrm{C}$ overnight, followed by incubation with a fluorescein-conjugated anti-mouse immunoglobulin G secondary antibody (dilution, 1:100; cat. no. 62-6511; Molecular Probes; Thermo Fisher Scientific, Inc.) in the dark at $37^{\circ} \mathrm{C}$ for $40 \mathrm{~min}$. In addition, BV2 cells were pretreated with or without $200 \mu \mathrm{M}$ isorhamnetin for $30 \mathrm{~min}$, followed by treatment with Alexa Fluor ${ }^{\circledR}$ (AF) 488-conjugated LPS (AF-LPS; $100 \mathrm{ng} / \mathrm{ml}$; Invitrogen; Thermo Fisher Scientific, Inc.) for $6 \mathrm{~h}$, in order to analyze the formation of LPS/TLR4 complexes. Fixed cells were also incubated with anti-TLR4 antibody (1:100; cat. no. ab8376; Abcam, Cambridge, UK) at $4^{\circ} \mathrm{C}$ for $90 \mathrm{~min}$ and were then incubated with AF 594-conjugated secondary antibody (1:100; cat. no. A-11032; Invitrogen; Thermo Fisher Scientific, Inc.) at room temperature for $1 \mathrm{~h}$. Nuclei were sequentially stained with DAPI (Sigma-Aldrich; Merck KGaA) solution $(2.5 \mu \mathrm{g} / \mathrm{ml})$. Slides were mounted and fluorescence images were captured under a fluorescence microscope (Zeiss AG, Oberkochen, Germany).

Measurement of TLR4 expression on the cell surface. To investigate the effects of isorhamnetin on TLR4 expression on the cell surface, BV2 cells were pretreated with or without $200 \mu \mathrm{M}$ isorhamnetin for $30 \mathrm{~min}$, followed by treatment with $100 \mathrm{ng} / \mathrm{ml}$ AF-LPS for $6 \mathrm{~h}$. Following treatment, cells $\left(5 \times 10^{5}\right.$ cells $\left./ \mathrm{ml}\right)$ were washed twice with PBS, harvested with $0.005 \%$ EDTA and analyzed by flow cytometry. AF 488 was excited using 488 argon-ion laser and detected on channel FL1 using a $530 \mathrm{~nm}$ emission filter. Fluorescence emission of samples was recorded by flow cytometry (BD Biosciences, San Jose, CA, USA), as previously described (30).

Detection of intracellular ROS levels. Production of intracellular ROS was monitored using 5,6-carboxy-2',7'dichlorofluorescin diacetate (DCF-DA; Sigma-Aldrich; Merck $\mathrm{KGaA}$ ), which is a cell-permeable fluorogenic probe. Briefly, cells were treated with $100 \mathrm{ng} / \mathrm{ml}$ LPS for the indicated time periods, or were pretreated with $200 \mu \mathrm{M}$ isorhamnetin or $10 \mathrm{mM} \mathrm{N}$-acetyl cysteine (NAC; Sigma-Aldrich; Merck KGaA) for $1 \mathrm{~h}$ followed by stimulation with or without $100 \mathrm{ng} / \mathrm{ml}$ LPS for $1 \mathrm{~h}$. These cells $\left(5 \times 10^{5}\right.$ cells $\left./ \mathrm{ml}\right)$ were harvested and stained with $10 \mu \mathrm{M}$ DCF-DA in the dark at $37^{\circ} \mathrm{C}$ for $15 \mathrm{~min}$. After rinsing twice with PBS, cells were immediately analyzed by flow cytometry with an excitation wavelength of $480 \mathrm{~nm}$ and an emission wavelength of $525 \mathrm{~nm}$. To observe the degree of ROS production by fluorescence microscopy, the coverslips were 
Table I. List of antibodies used for western blot analysis in the present study.

\begin{tabular}{|c|c|c|c|c|}
\hline Antibody & Dilution & Product no. & Species of origin & Supplier \\
\hline iNOS & $1: 1,000$ & 610328 & Rabbit polyclonal & $\begin{array}{l}\text { BD Transduction Laboratories; } \\
\text { BD Biosciences, San Jose, CA, USA }\end{array}$ \\
\hline COX-2 & $1: 500$ & 160126 & Rabbit polyclonal & $\begin{array}{l}\text { Cayman Chemical Company, } \\
\text { Ann Arbor, MI, USA }\end{array}$ \\
\hline IL-1 $\beta$ & $1: 1,000$ & sc-7884 & Rabbit polyclonal & $\begin{array}{l}\text { Santa Cruz Biotechnology, Inc., } \\
\text { Dallas, TX, USA }\end{array}$ \\
\hline TNF- $\alpha$ & $1: 1,000$ & $3707 \mathrm{~S}$ & Rabbit polyclonal & $\begin{array}{l}\text { Cell Signaling Technology, Inc., } \\
\text { Danvers, MA, USA }\end{array}$ \\
\hline $\mathrm{NF}-\kappa \mathrm{B}$ p 65 & $1: 1,000$ & sc-71675 & Mouse monoclonal & Santa Cruz Biotechnology, Inc. \\
\hline $\mathrm{I} \kappa \mathrm{B} \alpha$ & $1: 1,000$ & sc-371 & Rabbit polyclonal & Santa Cruz Biotechnology, Inc. \\
\hline $\mathrm{p}-\mathrm{I} \kappa \mathrm{B} \alpha$ & $1: 1,000$ & sc-8404 & Mouse monoclonal & Santa Cruz Biotechnology, Inc. \\
\hline TLR4 & $1: 1,000$ & ab53629 & Goat polyclonal & Abcam, Cambridge, MA, USA \\
\hline Myd88 & $1: 1,000$ & ab2064 & Rabbit polyclonal & Abcam \\
\hline Lamin B & $1: 1,000$ & sc-6216 & Goat polyclonal & Santa Cruz Biotechnology, Inc. \\
\hline Actin & $1: 1,000$ & sc-1615 & Goat polyclonal & Santa Cruz Biotechnology, Inc. \\
\hline
\end{tabular}

COX-2, cyclooxygenase-2; IкB- $\alpha$, inhibitor $\kappa$ B- $\alpha$; IL-1, interleukin-1; iNOS, inducible nitric oxide synthase; Myd88, myeloid differentiation factor 88; NF- $\kappa \mathrm{B}$, nuclear factor- $\kappa \mathrm{B}$; p, phosphorylated; TNF- $\alpha$, tumor necrosis factor- $\alpha$; TLR4, Toll-like receptor 4.

placed on a glass 6 -well plate, and the cells $\left(3 \times 10^{5}\right.$ cells $\left./ \mathrm{ml}\right)$ were incubated for $24 \mathrm{~h}$ to attach to the coverslips. The cells were treated with $100 \mathrm{ng} / \mathrm{ml}$ LPS for $1 \mathrm{~h}$, or were pretreated with $200 \mu \mathrm{M}$ isorhamnetin or $10 \mathrm{mM}$ NAC for $1 \mathrm{~h}$ followed by stimulation with or without $100 \mathrm{ng} / \mathrm{ml}$ LPS for $1 \mathrm{~h}$. These cells were stained with $10 \mu \mathrm{M}$ DCF-DA at $37^{\circ} \mathrm{C}$ for $15 \mathrm{~min}$, washed twice with PBS and fixed with $4 \%$ paraformaldehyde $(\mathrm{pH} 7.4)$ for $20 \mathrm{~min}$. Fixed cells were washed twice with PBS and were then analyzed by fluorescence microscopy.

Statistical analysis. Statistical analysis was conducted using GraphPad Prism version 6.02 (GraphPad Software, Inc., La Jolla, CA, USA). All data were collected from at least three independent experiments and are presented as the means \pm standard deviation. One-way analysis of variance with Tukey's multiple comparison post hoc test was performed to analyze the data. $\mathrm{P}<0.05$ was considered to indicate a statistically significant difference.

\section{Results}

Isorhamnetin suppresses LPS-induced pro-inflammatory mediators and cytokines production in BV2 microglial cells. To determine the inhibitory effects of isorhamnetin on LPS-induced production of $\mathrm{NO}$ and $\mathrm{PGE}_{2}$, which are pro-inflammatory mediators, BV2 cells were pretreated with various concentrations of isorhamnetin for $1 \mathrm{~h}$ and were then stimulated with or without $100 \mathrm{ng} / \mathrm{ml}$ LPS for $24 \mathrm{~h}$. Levels of $\mathrm{NO}$ and $\mathrm{PGE}_{2}$ in culture supernatants were determined using the Griess reaction assay and ELISA, respectively. As shown in Fig. 1A and B, LPS stimulation alone markedly increased $\mathrm{NO}$ and $\mathrm{PGE}_{2}$ production, as compared with in cells that were not stimulated by LPS. Conversely, isorhamnetin significantly inhibited LPS-induced secretion of NO and $\mathrm{PGE}_{2}$ in BV2 cells in a concentration-dependent manner. The effects of isorhamnetin on the production of pro-inflammatory cytokines, including TNF- $\alpha$ and IL-1 $\beta$, were also detected in LPS-stimulated BV2 cells. According to the results of ELISA, as shown in Fig. 1C and D, the production of these two cytokines was significantly increased in the culture medium of LPS-stimulated BV2 cells; however, isorhamnetin treatment decreased the production of these cytokines in a concentration-dependent manner.

Isorhamnetin attenuates LPS-induced iNOS, COX-2 and cytokine expression in BV2 microglial cells. The present study aimed to determine whether the inhibitory effects of isorhamnetin on $\mathrm{NO}$ and $\mathrm{PGE}_{2}$ production were associated with regulation of iNOS and COX-2 expression. As shown in Fig. 2, isorhamnetin inhibited the mRNA and protein expression levels of iNOS and COX-2 in LPS-stimulated BV2 cells in a concentration-dependent manner. In addition, isorhamnetin inhibited LPS-induced increased expression of TNF- $\alpha$ and IL-1 $\beta$ in a concentration-dependent manner (Fig. 2). These findings indicated that isorhamnetin may suppress $\mathrm{NO}, \mathrm{PGE}_{2}$ and cytokine production by reducing the expression of their encoding genes.

Effect of isorhamnetin on the viability of BV2 microglial cells. The MTT assay was performed to investigate whether the inhibitory effects of isorhamnetin on production of pro-inflammatory mediators and cytokines were caused by cytotoxicity. As shown in Fig. 3, the survival rate of BV2 cells was not significantly affected by treatment with $\geq 200 \mu \mathrm{M}$ isorhamnetin alone for $24 \mathrm{~h}$. In addition, no significant alteration in survival rate was detected in BV2 cells treated with $\geq 200 \mu \mathrm{M}$ isorhamnetin, even in the presence of $100 \mathrm{ng} / \mathrm{ml} \mathrm{LPS}$.

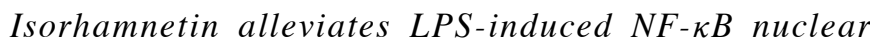
translocation and inhibitor $\kappa B-\alpha(I \kappa B \alpha)$ degradation in 

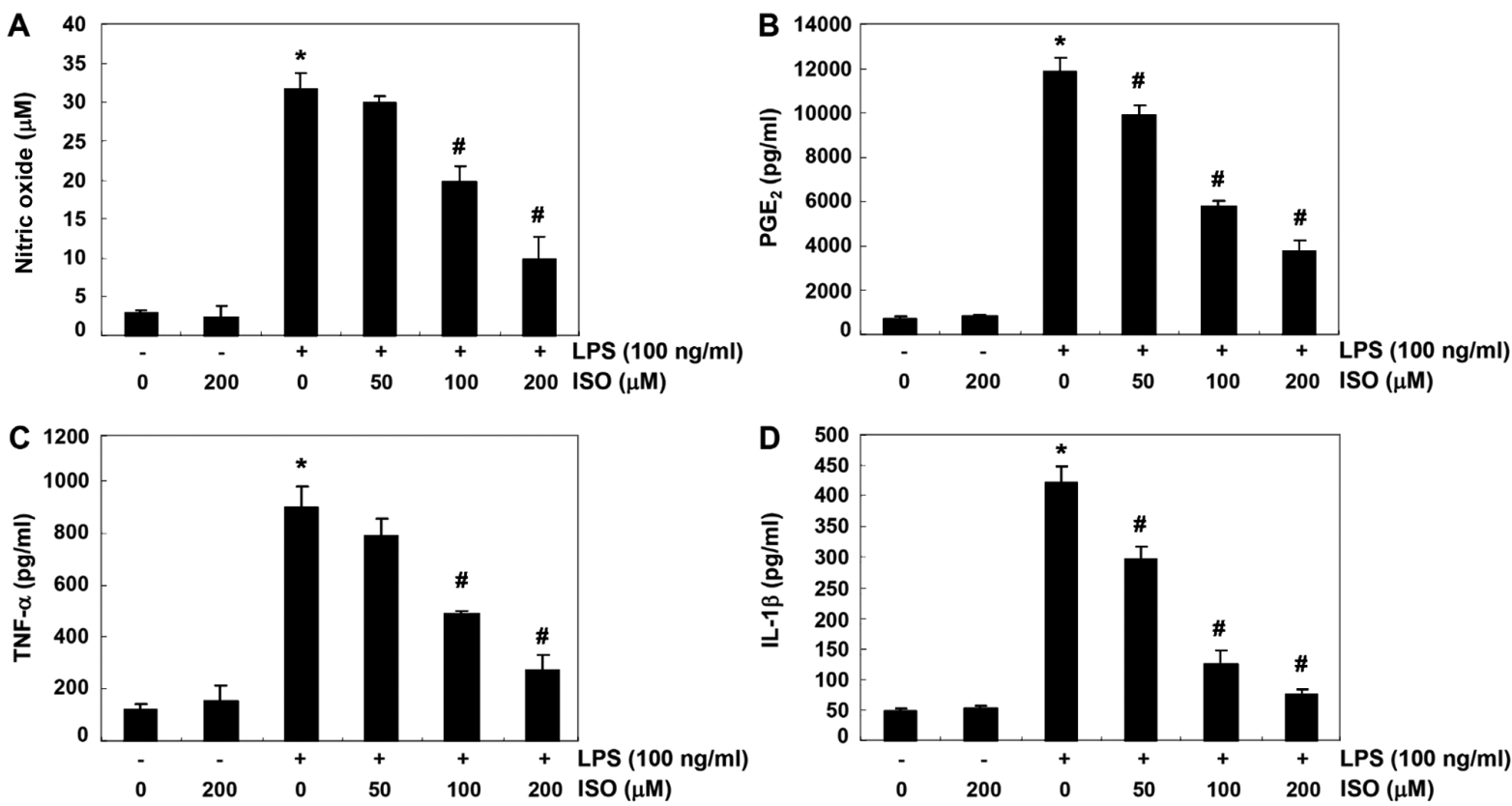

Figure 1. Suppression of NO, PGE 2 , TNF- $\alpha$ and IL-1 $\beta$ production by ISO in LPS-stimulated BV2 microglial cells. Cells were pretreated with the indicated

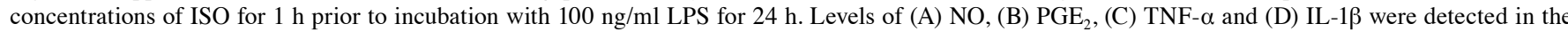
culture media by Griess assay and commercial ELISA kits. Data are presented as the means \pm standard deviation obtained from three independent experiments. "P<0.05 compared with the control group; ${ }^{*} \mathrm{P}<0.05$ compared with the LPS group. IL-1 $\beta$, interleukin-1 $\beta$; ISO, isorhamnetin; LPS, lipopolysaccharide; $\mathrm{NO}$, nitric oxide; $\mathrm{PGE}_{2}$, prostaglandin $\mathrm{E}_{2}$; TNF- $\alpha$, tumor necrosis factor- $\alpha$.

BV2 microglial cells. The present study aimed to determine whether isorhamnetin could attenuate LPS-induced activation of $\mathrm{NF}-\kappa \mathrm{B}$ in $\mathrm{BV} 2$ cells. Immunoblotting data using cytoplasmic and nuclear extracts revealed that pretreatment with isorhamnetin inhibited nuclear accumulation of NF- $\kappa \mathrm{B}$ p65 subunits in LPS-stimulated BV2 cells. In addition, isorhamnetin attenuated the LPS-induced inhibition of total $\mathrm{I} \kappa \mathrm{B} \alpha$ protein expression and reduced phosphorylation of $\mathrm{I} \kappa \mathrm{B} \alpha$ (Fig. 4A and B). Consistent with these results, immunocytochemical analysis indicated that the fluorescence intensity of $\mathrm{NF}-\kappa \mathrm{B}$ p65 in the nucleus was increased in LPS-stimulated cells. However, LPS-mediated nuclear translocation of NF- $\mathrm{B}$ was considerably blocked by pretreatment with isorhamnetin (Fig. 4C), thus indicating that isorhamnetin could attenuate transcriptional activation of $\mathrm{NF}-\kappa \mathrm{B}$.

Isorhamnetin inhibits LPS-induced TLR4 and Myd88 expression in BV2 microglial cells. To determine whether the anti-inflammatory effects of isorhamnetin were associated with blockade of the TLR signaling pathway, the expression levels of TLR4 and myeloid differentiation factor 88 (Myd88) were investigated (Fig. 5). The results of immunoblotting revealed that protein expression levels of TLR4 and Myd88 were markedly increased by LPS treatment in a time-dependent manner (Fig. 5A and C). However, when cells were pretreated with isorhamnetin, the LPS-induced increase in TLR4 and Myd88 expression was inhibited in a concentration-dependent manner (Fig. 5B and D).

Isorhamnetin blocks LPS-mediated interaction between LPS and TLR4 in BV2 microglial cells. The present study assessed whether isorhamnetin could inhibit the interaction between LPS and TLR4 on the surface of LPS-treated BV2 cells. As shown in Fig. 6A and B, fluorescence of LPS and TLR4 was observed outside the cell membrane in BV2 cells treated with AF-LPS. However, the fluorescence intensity of TLR4 and the binding activity of LPS on the cell surface were markedly attenuated in BV2 cells treated with LPS in the presence of isorhamnetin.

Interception of TLR4 signaling increases the anti-inflammatory efficacy of isorhamnetin on BV2 microglial cells. To further determine whether blockade of TLR4 signaling is mediated by the anti-inflammatory action of isorhamnetin, the present study examined the effects of the TLR4 antagonist, CLI-095, on isorhamnetin-induced inhibition of inflammatory mediators. As shown in Fig. 7A and B, CLI-095 significantly reduced the production of LPS-induced inflammatory mediators, such as $\mathrm{NO}$ and $\mathrm{PGE}_{2}$, Furthermore, cotreatment with isorhamnetin and CLI-095 synergistically inhibited LPS-induced production of $\mathrm{NO}$ and $\mathrm{PGE}_{2}$ and blocked the transcription of corresponding genes (Fig. 7C and D). These results suggested that the inhibitory effects of isorhamnetin on LPS-induced inflammation may be due to suppression of the TLR4-mediated NF- $\kappa \mathrm{B}$ signaling pathway in BV2 microglia.

Isorhamnetin reduces LPS-induced ROS generation in BV2 microglial cells. The present study also examined the effects of isorhamnetin on LPS-induced ROS production, in order to investigate the antioxidant potential of isorhamnetin. Flow cytometry using the fluorescent probe DCF-DA revealed that the levels of ROS were gradually increased following treatment with LPS, peaking at $1 \mathrm{~h}$; thereafter, ROS levels were decreased (Fig. 8A). Conversely, treatment with isorhamnetin alone did not induce ROS generation. Pretreatment with isorhamnetin effectively attenuated the levels of ROS released by 
A

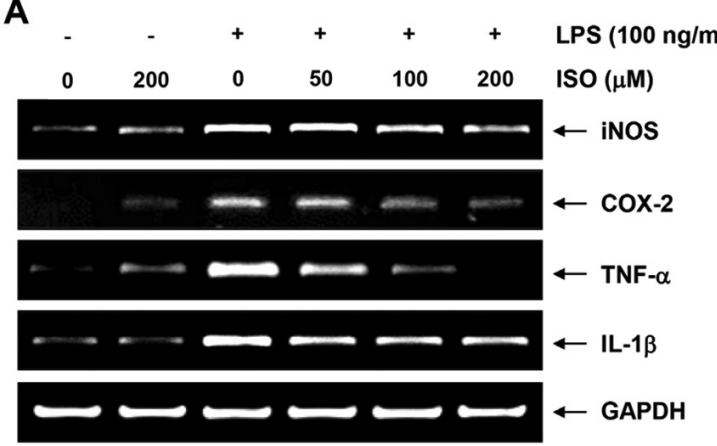

B

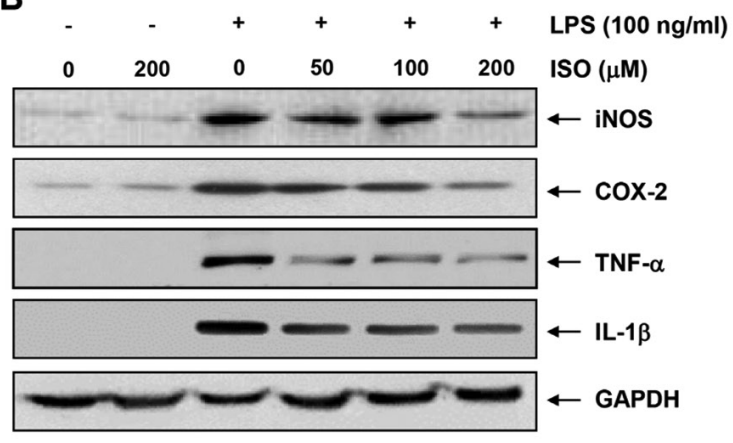

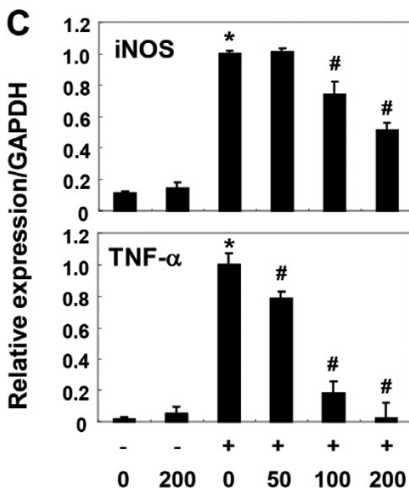
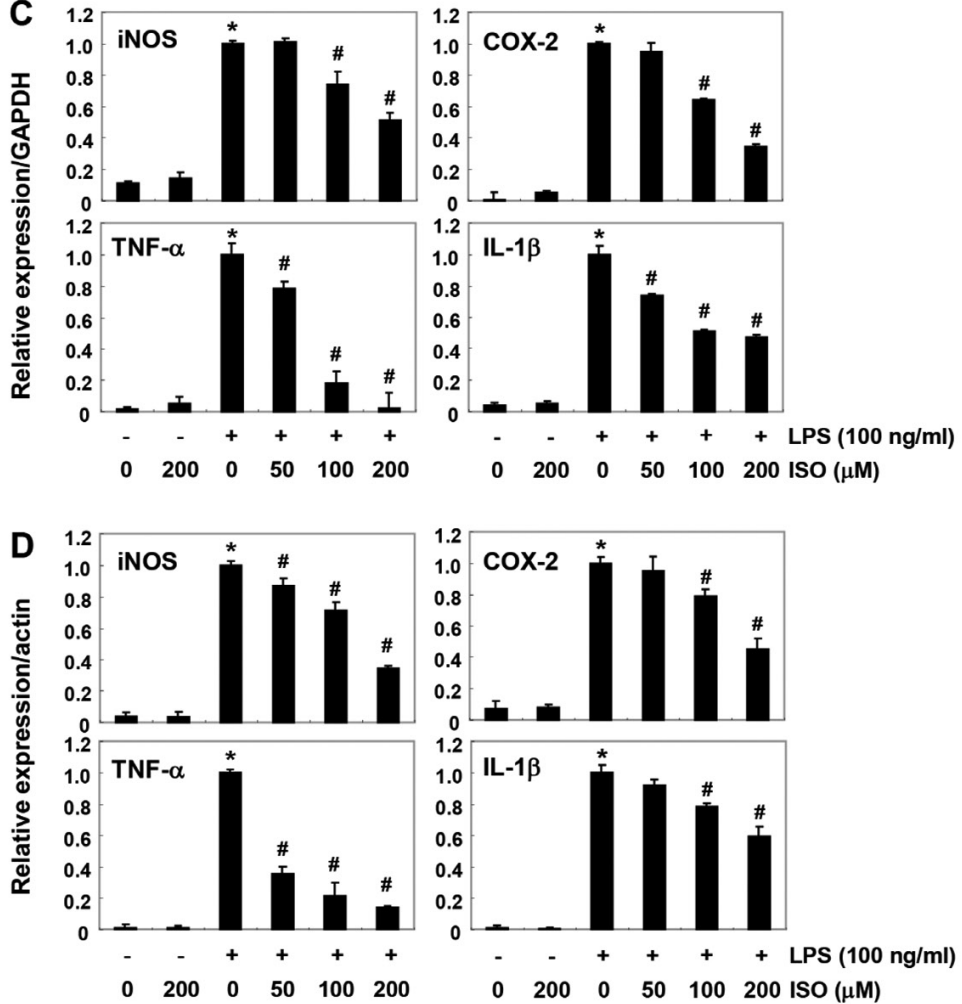

Figure 2. Inhibition of LPS-induced expression of iNOS, COX-2, TNF- $\alpha$ and IL-1 $\beta$ by ISO in BV2 microglial cells. BV2 cells were pretreated with various concentrations of ISO for $1 \mathrm{~h}$ followed by treatment with $100 \mathrm{ng} / \mathrm{ml} \mathrm{LPS} \mathrm{for} 24 \mathrm{~h}$. (A) Total RNA was isolated and RT-PCR was performed using the indicated primers. (B) Total proteins were isolated and subjected to western blot analyses. Experiments were repeated three times and similar results were obtained. GAPDH and actin were used as the internal controls for the RT-PCR and western blot analysis, respectively. Bands were semi-quantified using ImageJ, normalized to (C) GAPDH and (D) actin and ratios were determined. Data are presented as the means \pm standard deviation obtained from three independent experiments. ${ }^{*} \mathrm{P}<0.05$ compared with the control group; ${ }^{\#} \mathrm{P}<0.05$ compared with the LPS group. COX-2, cyclooxygenase $2 ;$ IL-1 $\beta$, interleukin-1 $\beta$; ISO, isorhamnetin; LPS, lipopolysaccharide; NO, nitric oxide; $\mathrm{PGE}_{2}$, prostaglandin $\mathrm{E}_{2}$; RT-PCR, reverse transcription-polymerase chain reaction; TNF- $\alpha$, tumor necrosis factor- $\alpha$.
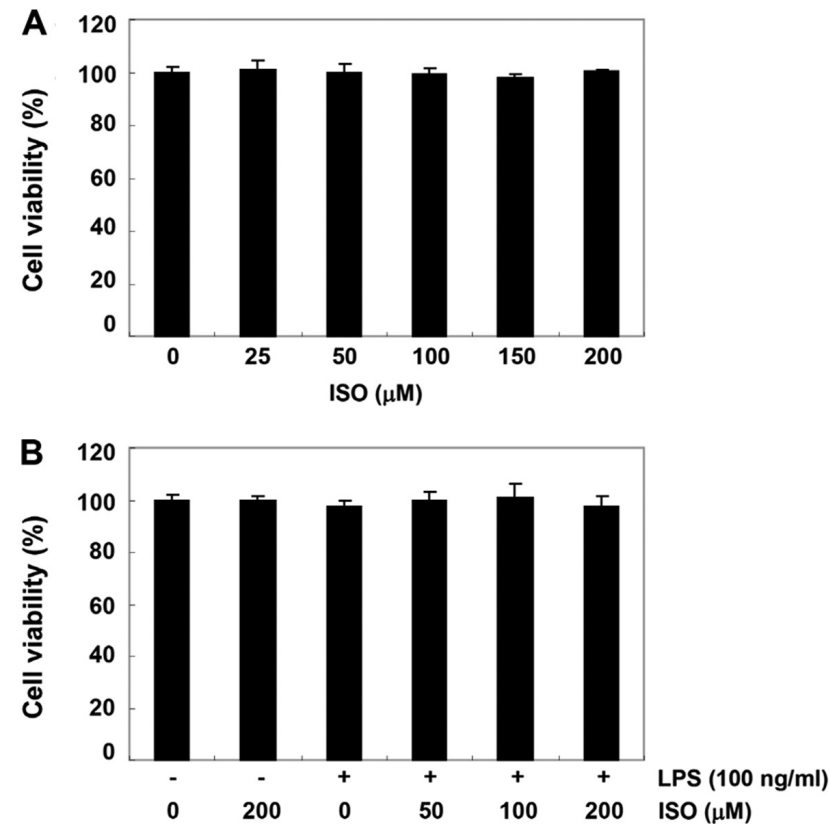

Figure 3. Effects of ISO and LPS on the viability of BV2 microglial cells. Cells were (A) treated with various concentrations of ISO for $24 \mathrm{~h}$ or (B) were pretreated with the indicated concentrations of ISO for $1 \mathrm{~h}$ prior to treatment with $100 \mathrm{ng} / \mathrm{ml}$ LPS for $24 \mathrm{~h}$. Cell viability was assessed by MTT assay. Results are expressed as the percentage of surviving cells over control cells. Data are presented as the means \pm standard deviation of three independent experiments. ISO, isorhamnetin; LPS, lipopolysaccharide.
LPS (Fig. 8B). The inhibitory effects of isorhamnetin on ROS production were also observed under fluorescence microscopy (Fig. 8C). In NAC-pretreated cells, which were used as a positive control, the production of LPS-stimulated ROS was completely blocked. These findings indicated that isorhamnetin had a strong ROS-scavenging effect.

\section{Discussion}

The results of the present study demonstrated that isorhamnetin inhibited LPS-induced inflammatory signaling in BV2 microglia, a brain microglial cell line. Similar to the results of previous studies using macrophage and gingival fibroblast models $(14,31)$, the present results indicated that isorhamnetin could significantly inhibit the increased production of $\mathrm{NO}$ and $\mathrm{PGE}_{2}$ by LPS, in the absence of cytotoxicity, which was associated with suppression of iNOS and COX-2 expression, respectively. In addition, isorhamnetin reduced the release of TNF- $\alpha$ and IL-1 $\beta$ by blocking their expression in LPS-stimulated microglial cells; these findings are also similar to the results of previous studies $(17,26)$. These results suggested that isorhamnetin may improve the inflammatory response by inhibiting the expression of genes that regulate the production of pro-inflammatory factors.

$\mathrm{NF}-\mathrm{KB}$ is a key transcription factor that increases the expression of pro-inflammatory enzymes and cytokines only 
A

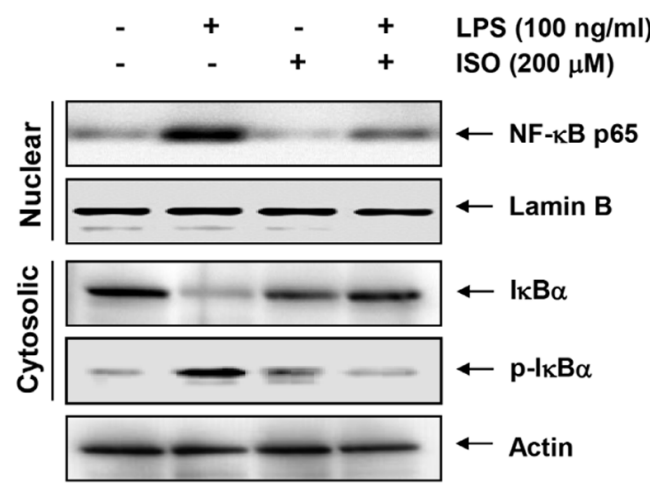

C
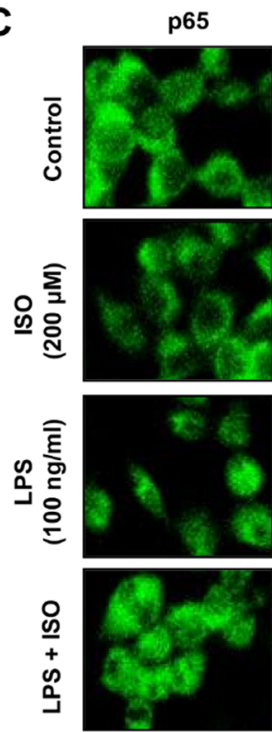

DAPI
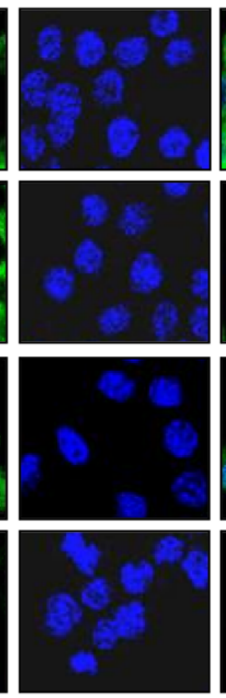

Merged
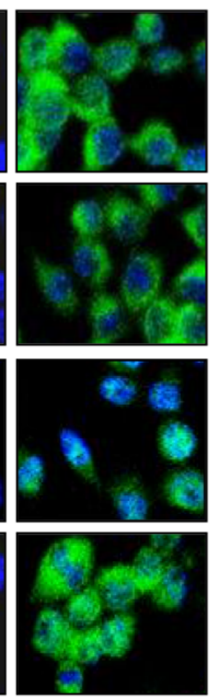

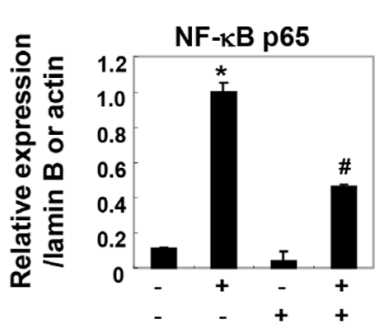

$\mathrm{I} \kappa \mathrm{B} \alpha$

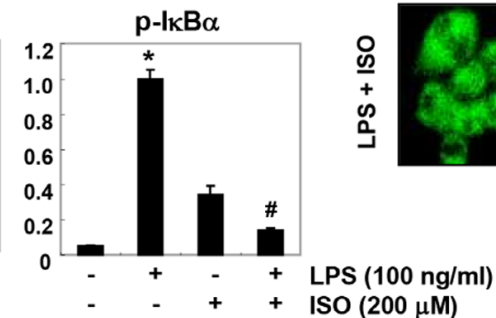

Figure 4. Inhibition of NF- $\kappa \mathrm{B}$ nuclear translocation by isorhamnetin in LPS-stimulated BV2 microglial cells. (A) Cells were pretreated with $200 \mu \mathrm{M}$ isorhamnetin for $1 \mathrm{~h}$ prior to treatment with $100 \mathrm{ng} / \mathrm{ml} \mathrm{LPS}$ for $1 \mathrm{~h}$. Nuclear and cytosolic proteins were prepared for western blot analysis using anti-NF- $\mathrm{B}$ p65 and anti-I $\mathrm{B} \alpha$ antibodies. Lamin B and actin were used as internal controls for nuclear and cytosolic fractions, respectively. (B) Bands were semi-quantified using Image J, normalized to lamin B and actin and the ratios were determined. Data are presented as the means \pm standard deviation of three independent experiments. ${ }^{*} \mathrm{P}<0.05$ compared with the control group; ${ }^{\#} \mathrm{P}<0.05$ compared with the LPS group. (C) Cells were pretreated with $200 \mu \mathrm{M}$ isorhamnetin for $1 \mathrm{~h}$ prior to treatment with $100 \mathrm{ng} / \mathrm{ml}$ LPS for $1 \mathrm{~h}$. Localization of NF- $\kappa \mathrm{B}$ p 65 was visualized by fluorescence microscopy (original magnification, $\mathrm{x} 400$ ) following immunofluorescence staining with an anti-NF- $\kappa \mathrm{B}$ p65 antibody (green). The cells were also stained with DAPI to visualize nuclei (blue). Results are representative of three independent experiments. ISO, isorhamnetin; LPS, lipopolysaccharide; NF- $\kappa \mathrm{B}$, nuclear factor- $\kappa \mathrm{B}$; I $\mathrm{B} \alpha$, inhibitor $\kappa \mathrm{B}-\alpha$; $\mathrm{p}$, phosphorylated.

A

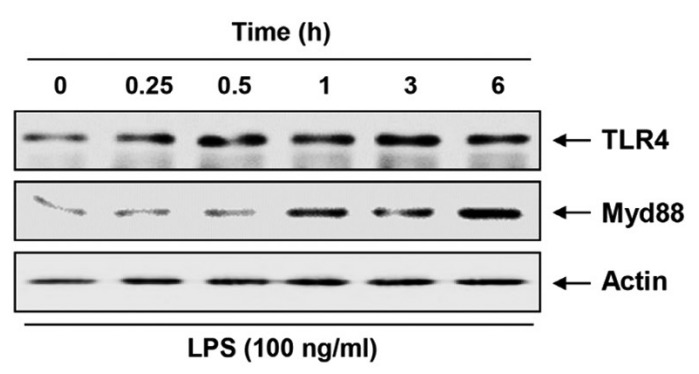

C
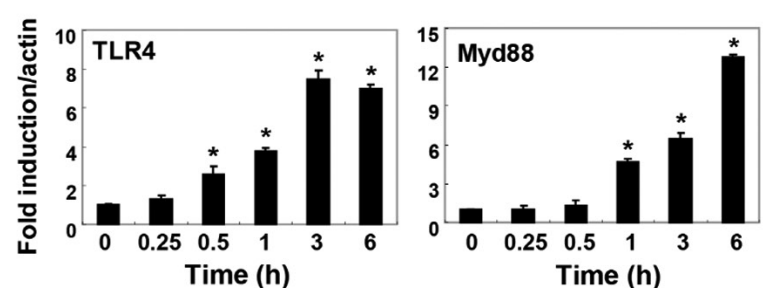

B

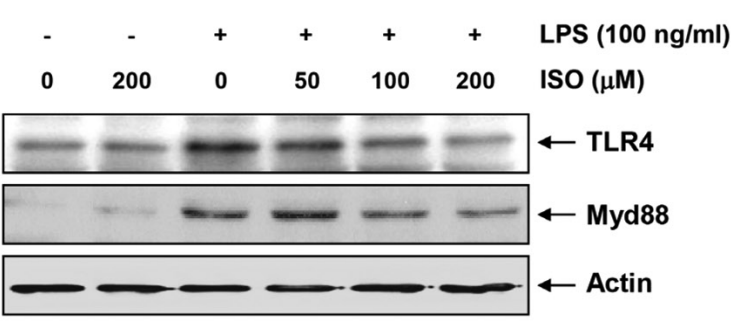

D
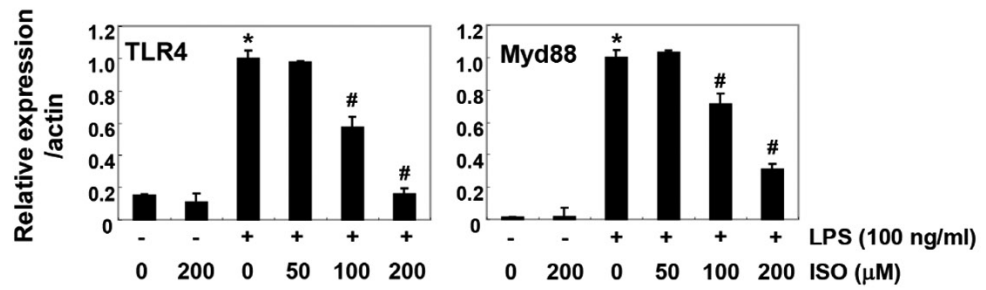

Figure 5. Effects of isorhamnetin on LPS-induced expression of TLR4 and Myd88 in BV2 microglial cells. Cells were (A) treated with 100 ng/ml LPS for the indicated duration or (B) pretreated with the indicated concentrations of isorhamnetin for $1 \mathrm{~h}$ prior to $100 \mathrm{ng} / \mathrm{ml} \mathrm{LPS}$ treatment for $6 \mathrm{~h}$. Total proteins were prepared for western blot analysis using anti-TLR4 and anti-Myd88 antibodies. Actin was used as an internal control. (C and D) Bands were semi-quantified using ImageJ, normalized to actin and the ratios were determined. Data are presented as the means \pm standard deviation of three independent experiments. ${ }^{*} \mathrm{P}<0.05$ compared with the control group; ${ }^{\#} \mathrm{P}<0.05$ compared with the LPS group. ISO, isorhamnetin; LPS, lipopolysaccharide; Myd88, myeloid differentiation factor 88; TLR4, Toll-like receptor 4 .

if it has migrated to the nucleus. NF- $\mathrm{B}$ is usually located in

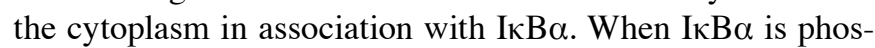
phorylated and degraded, $N F-\kappa B$ is isolated and translocated to the nucleus (5-7). Therefore, this study aimed to determine whether isorhamnetin could inhibit LPS-induced degradation and phosphorylation of $\mathrm{I} \kappa \mathrm{B} \alpha$ and nuclear translocation 

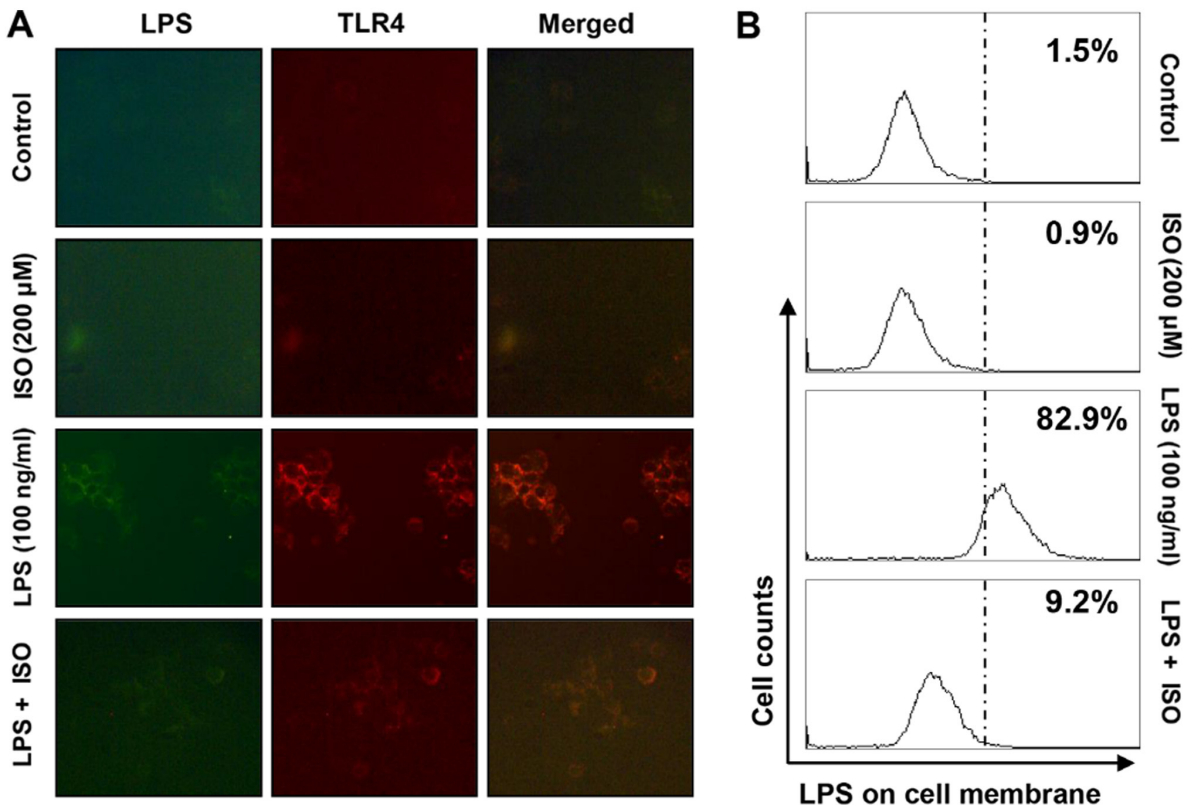

Figure 6. LPS-induced interaction between LPS and TLR4 is attenuated by isorhamnetin in BV2 microglial cells. (A) BV2 cells were pretreated with or without $200 \mu \mathrm{M}$ isorhamnetin for $30 \mathrm{~min}$, followed by treatment with $100 \mathrm{ng}$ AF-LPS for $6 \mathrm{~h}$. The distribution of AF-LPS and TLR4 was detected by fluorescence microscopy (original magnification, $\mathrm{x} 200$ ). Experiments were repeated three times with similar results. (B) Cells were pretreated with or without $200 \mu \mathrm{M}$ isorhamnetin for $30 \mathrm{~min}$, followed by treatment with $100 \mathrm{ng} / \mathrm{ml}$ AF-LPS for $6 \mathrm{~h}$. LPS binding on the surface of BV2 cells was measured by flow cytometry. Values represent the means of two independent experiments. AF-LPS, Alexa Fluor ${ }^{\circledR}$ 488-conjugated LPS; ISO, isorhamnetin; LPS, lipopolysaccharide; TLR4, Toll-like receptor 4.

A

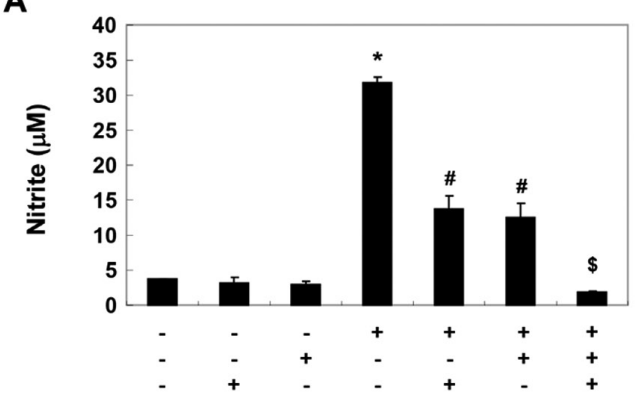

C

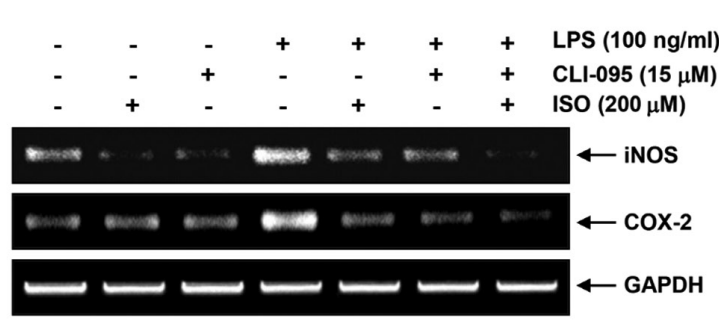

B

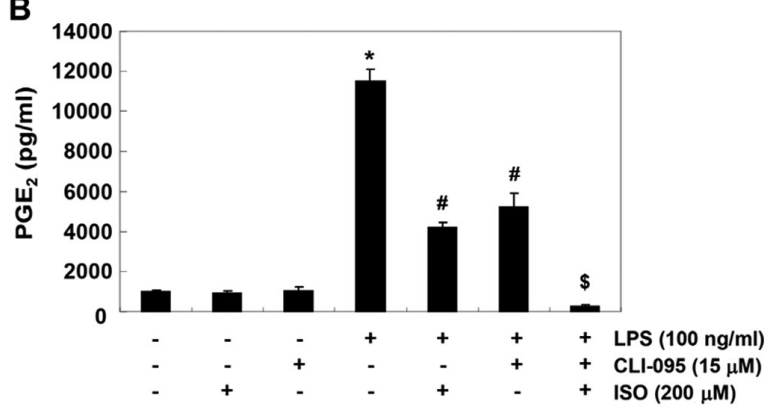

D

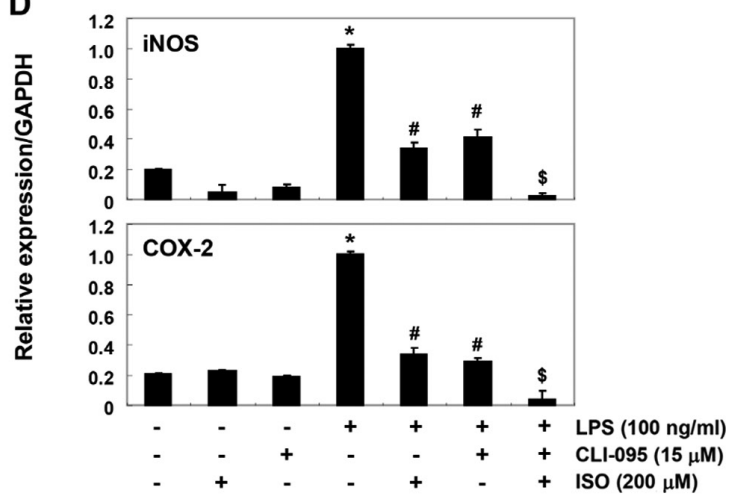

Figure 7. Effects of the TLR4 inhibitor, CLI-095, on LPS-induced production of pro-inflammatory mediators in BV2 microglia. (A and B) BV2 cells were treated with the indicated concentrations of ISO $(200 \mu \mathrm{M})$ alone or in combination with CLI-095 $(15 \mu \mathrm{M})$ for $1 \mathrm{~h}$ prior to treatment with LPS for $24 \mathrm{~h}$. The levels of nitric oxide and $\mathrm{PGE}_{2}$ in the culture media were measured by Griess assay and a PGE ${ }_{2}$ ELISA kit. (C) mRNA expression levels of iNOS and COX-2 were assessed by reverse transcription-polymerase chain reaction. GAPDH was used as an internal control. (D) Bands were semi-quantified using ImageJ, normalized to GAPDH and the ratios were determined. Data are presented as the means \pm standard deviation of three independent experiments. " $\mathrm{P}<0.05$ compared with the control group; ${ }^{\mathrm{P}} \mathrm{P}<0.05$ compared with the LPS group; ${ }^{\text {P }}<0.05$ compared with the LPS+ISO group. CLI-095 ethyl-(6R)-6-(N-(2-chloro-4-fluorophenyl)sulfamoyl) cyclohex-1-ene-1-carboxylate; COX-2, cyclooxygenase-2; iNOS, inducible nitric oxide synthase; ISO, isorhamnetin; LPS, lipopolysaccharide; PGE $_{2}$, prostaglandin $\mathrm{E}_{2}$.

of NF- $\kappa$ B. The results indicated that isorhamnetin could effectively block nuclear expression of NF- $\mathrm{BB}$ (p65), and the degradation and phosphorylation of IкB $\alpha$ in LPS-stimulated BV2 microglial cells. These results suggested that isorhamnetin 
A

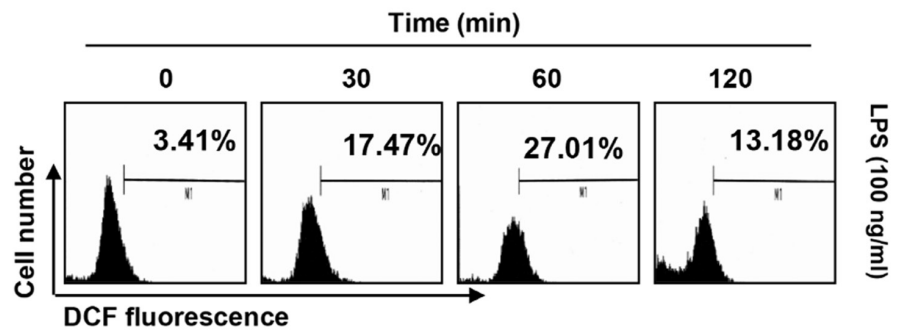

B

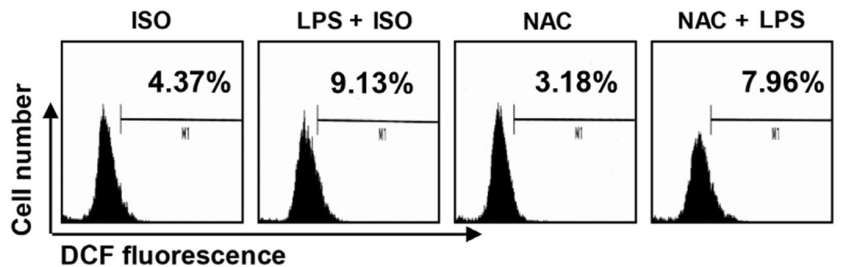

C Control

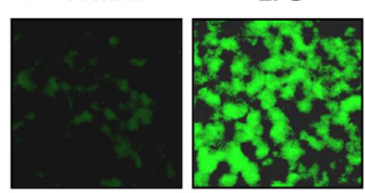

ISO

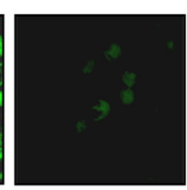

LPS + ISO

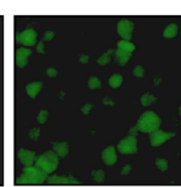

NAC

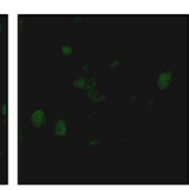

NAC + LPS

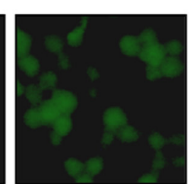

Figure 8. LPS-induced ROS generation is inhibited by ISO in BV2 microglial cells. Cells were (A) treated with $100 \mathrm{ng} / \mathrm{ml} \mathrm{LPS} \mathrm{for} \mathrm{the} \mathrm{indicated} \mathrm{time} \mathrm{periods}$ or (B) pretreated with $200 \mu \mathrm{M}$ ISO or $10 \mathrm{mM} \mathrm{NAC}$ for $1 \mathrm{~h}$ followed by stimulation with or without $100 \mathrm{ng} / \mathrm{ml} \mathrm{LPS} \mathrm{for} 1 \mathrm{~h}$. (A and B) Cells were incubated with DCF-DA and DCF fluorescence was measured by flow cytometry. These values represent the means of two independent experiments. (C) After staining with DCF-DA, images were obtained by fluorescence microscopy (original magnification, $\mathrm{x} 200$ ). These images are representatives of at least three independent experiments. DCF-DA, 5,6-carboxy-2',7'-dichlorofluorescin diacetate; ISO, isorhamnetin; LPS, lipopolysaccharide; NAC, N-acetylcysteine.

may reduce the expression and production of pro-inflammatory mediators and cytokines by inhibiting the NF- $\mathrm{B}$ pathway in LPS-stimulated BV2 microglia. This is in agreement with previous results observed in LPS-stimulated macrophages and human umbilical vein endothelial cells $(20,26,27)$.

Immune cells, including microglia, can recognize pathogen-associated molecular patterns through TLR pattern recognition receptors, which are expressed on the cell surface. Among various TLRs, TLR4 is known to recruit adapter molecules, including MyD88, LPS-binding protein and differentiation cluster co-receptor, when immune cells are activated by LPS $(1,2)$. Upon activation of TLR4 by LPS, the TLR4-MyD88-mediated signal can induce activation of mitogen-activated protein kinases (MAPKs), which eventually promote the activation of $\mathrm{NF}-\kappa \mathrm{B}$ signaling, resulting in the production of pro-inflammatory mediators and cytokines $(4,32)$. According to the results of Yang et al (20), isorhamnetin can significantly inhibit LPS-mediated activation of the MAPK c-Jun N-terminal kinase in a macrophage model. The present study revealed that isorhamnetin suppressed LPS-induced expression of TLR4 and MyD88, and reduced the binding of TLR4 to LPS. These findings indicated that isorhamnetin may inhibit the expression of pro-inflammatory enzymes and cytokines by blocking the TLR4 signaling pathway, which is the early stage of intracellular signaling in LPS-stimulated cells. This finding demonstrated that isorhamnetin attenuated onset of the LPS-mediated intracellular signaling pathway by suppressing activation of $\mathrm{NF}-\kappa \mathrm{B}$ and inhibiting the binding of LPS to TLR4 in microglial cells. Therefore, isorhamnetin may to inhibit NF- $\kappa \mathrm{B}$ and MAPK signaling pathways by exhibiting antagonistic effects on the binding of LPS to TLR4 in BV2 microglial cells.
Alongside inflammatory insults, oxidative stress is another major cause of CNS damage. Low levels of ROS serve an important role as signaling molecules that regulate the immune response to pathogens; however, overproduction of ROS contributes to neurotoxicity (8,33-35). Previous studies have reported that the LPS-induced inflammatory response in microglia is directly associated with increased ROS production and that inhibition of the inflammatory response is associated with blocking ROS production $(14,32,36,37)$. TLR4 signaling-mediated generation of ROS by LPS accelerates the inflammatory response by activating downstream signaling cascades containing NF- $\kappa \mathrm{B}(38-40)$. Therefore, inhibiting ROS production is an important strategy to suppress inflammatory responses and oxidative stress. Previous studies using various research models have demonstrated that isorhamnetin possesses strong antioxidant efficacy. For example, the beneficial effects of isorhamnetin on LPS-induced acute lung injury and collagen-induced arthritis mouse models are directly associated with its antioxidant effects $(18,41)$. In addition, the protective effects of isorhamnetin on oxidative stress-induced DNA damage and apoptosis are associated with blocking of ROS production $(22,26,42)$. These results are in agreement with the antioxidant efficacy of isorhamnetin observed in the present study, indicating that isorhamnetin may effectively block the production of excessive ROS induced by LPS. To the best of our knowledge, the present study is the first to report on the inhibitory effects of isorhamnetin on ROS production in microglia; however, additional studies are required to determine the direct linkage between ROS production blockade and anti-inflammatory efficacy.

In conclusion, the present study demonstrated that isorhamnetin exerted potent anti-inflammatory effects on BV2 
microglial cells. In LPS-stimulated BV2 cells, isorhamnetin was able to reduce the production of pro-inflammatory mediators and cytokines, which was associated with decreased expression of their regulatory genes via the suppression of $\mathrm{NF}-\kappa \mathrm{B}$ activity. Furthermore, isorhamnetin could block early intracellular signaling cascades by antagonizing TLR4 or suppressing ROS accumulation. Although the results of the current study may provide partial understanding of the mechanism underlying the anti-inflammatory effects of isorhamnetin, further studies are required to assess the mechanical role of isorhamnetin in various oxidative stress- and inflammation-mediated diseases.

\section{Acknowledgements}

Not applicable.

\section{Funding}

This study was supported by the Basic Science Research Program through the National Research Foundation of Korea (NRF) grant funded by the Korean government (grant nos. 2018R1A2B2005705 and 2016R1A5A2007009).

\section{Availability of data and materials}

The datasets used and/or analyzed during the current study are available from the corresponding author on reasonable request.

\section{Authors' contributions}

SYK, HTP and YHC contributed to the conception and design of the experiment. SYK, CYJ, CHK, YHY and GYK performed all experiments and verified the analytical data. HMY and SHC contributed to the statistical analysis and helped interpret the results. YHC supervised the experiments in discussion with SYK, HTP, YHC, CYJ, CHK, YHY and GYK wrote the manuscript. All authors discussed the final results and approved the final manuscript.

\section{Ethics approval and consent to participate}

Not applicable.

\section{Patient consent for publication}

Not applicable.

\section{Competing interests}

The authors declare that they have no competing interests.

\section{References}

1. Tremblay MÈ, Stevens B, Sierra A, Wake H, Bessis A and Nimmerjahn A: The role of microglia in the healthy brain. J Neurosci 31: 16064-16069, 2011.

2. Gomez-Nicola D and Perry VH: Microglial dynamics and role in the healthy and diseased brain: A paradigm of functional plasticity. Neuroscientist 21: 169-184, 2015.

3. Glass CK, Saijo K, Winner B, Marchetto MC and Gage FH: Mechanisms underlying inflammation in neurodegeneration. Cell 140: 918-934, 2010.
4. Cherry JD, Olschowka JA and O'Banion MK: Neuroinflammation and M2 microglia: The good, the bad, and the inflamed. J Neuroinflammation 11: 98, 2014.

5. Li Q and Verma IM: NF-kappaB regulation in the immune system. Nat Rev Immunol 2: 725-734, 2002.

6. Kopitar-Jerala N: Innate immune response in brain, NF-Kappa B signaling and cystatins. Front Mol Neurosci 8: 73, 2015.

7. Lee MB, Lee JH, Hong SH, You JS, Nam ST, Kim HW, Park YH, Lee D, Min KY, Park YM, et al: JQ1, a BET inhibitor, controls TLR4-induced IL-10 production in regulatory $B$ cells by BRD4-NF- $\kappa$ B axis. BMB Rep 50: 640-646, 2017.

8. von Bernhardi R, Eugenín-von Bernhardi L and Eugenín J: Microglial cell dysregulation in brain aging and neurodegeneration. Front Aging Neurosci 7: 124, 2015.

9. Daulatzai MA: Fundamental role of pan-inflammation and oxidative-nitrosative pathways in neuropathogenesis of Alzheimer's disease in focal cerebral ischemic rats. Am J Neurodegener Dis 5: 102-130, 2016.

10. Choi HI, Choi JP, Seo J, Kim BJ, Rho M, Han JK and Kim JG: Helicobacter pylori-derived extracellular vesicles increased in the gastric juices of gastric adenocarcinoma patients and induced inflammation mainly via specific targeting of gastric epithelial cells. Exp Mol Med 49: e330, 2017.

11. Gu Y, Chen J and Shen J: Herbal medicines for ischemic stroke: Combating inflammation as therapeutic targets. J Neuroimmune Pharmacol 9: 313-339, 2014.

12. Chen J, Zhang X, Zhang C, Wang W, Chen R, Jiao H, Li L, Zhang L and Cui L: Anti-inflammation of natural components from medicinal plants at low concentrations in brain via inhibiting neutrophil infiltration after stroke. Mediators Inflamm 2016: 9537901, 2016.

13. Du L, Zhang Y, Chen Y, Zhu J, Yang Y and Zhang HL: Role of microglia in neurological disorders and their potentials as a therapeutic target. Mol Neurobiol 54: 7567-7584, 2017.

14. Qi F, Sun JH, Yan JQ, Li CM and Lv XC: Anti-inflammatory effects of isorhamnetin on LPS-stimulated human gingival fibroblasts by activating Nrf2 signaling pathway. Microb Pathog 120: 37-41, 2018

15. Wang J, Gong HM, Zou HH, Liang L and Wu XY: Isorhamnetin prevents $\mathrm{H}_{2} \mathrm{O}_{2}$-induced oxidative stress in human retinal pigment epithelial cells. Mol Med Rep 17: 648-652, 2018.

16. Ahn H and Lee GS: Isorhamnetin and hyperoside derived from water dropwort inhibits inflammasome activation. Phytomedicine 24: 77-86, 2017.

17. Chi G, Zhong W, Liu Y, Lu G, Lü H, Wang D and Sun F: Isorhamnetin protects mice from lipopolysaccharide-induced acute lung injury via the inhibition of inflammatory responses. Inflamm Res 65: 33-41, 2016.

18. Yang B, Li XP, Ni YF, Du HY, Wang R, Li MJ, Wang WC, Li MM, Wang XH, Li L, et al: Protective effect of isorhamnetin on lipopolysaccharide-induced acute lung injury in mice. Inflammation 39: 129-137, 2016.

19. Zhao JJ, Song JQ, Pan SY and Wang K: Treatment with isorhamnetin protects the brain against ischemic injury in mice. Neurochem Res 41: 1939-1948, 2016.

20. Yang JH, Kim SC, Shin BY, Jin SH, Jo MJ, Jegal KH, Kim YW, Lee JR, Ku SK, Cho IJ, et al: O-Methylated flavonol isorhamnetin prevents acute inflammation through blocking of NF- $\mathrm{BB}$ activation. Food Chem Toxicol 59: 362-372, 2013.

21. Seo S, Seo K, Ki SH and Shin SM: Isorhamnetin inhibits reactive oxygen species-dependent hypoxia inducible factor (HIF)-1a accumulation. Biol Pharm Bull 39: 1830-1838, 2016.

22. Choi YH: The cytoprotective effect of isorhamnetin against oxidative stress is mediated by the upregulation of the Nrf2-dependent HO-1 expression in C2C12 myoblasts through scavenging reactive oxygen species and ERK inactivation. Gen Physiol Biophys 35: 145-154, 2016.

23. Chen TL, Zhu GL, Wang JA, Zhang GD, Liu HF, Chen JR, Wang Y and He XL: Protective effects of isorhamnetin on apoptosis and inflammation in TNF- $\alpha$-induced HUVECs injury. Int J Clin Exp Pathol 8: 2311-2320, 2015.

24. Seo K, Yang JH, Kim SC, Ku SK, Ki SH and Shin SM: The antioxidant effects of isorhamnetin contribute to inhibit COX-2 expression in response to inflammation: A potential role of HO-1. Inflammation 37: 712-722, 2014.

25. Qin L, Liu Y, Hong JS and Crews FT: NADPH oxidase and aging drive microglial activation, oxidative stress, and dopaminergic neurodegeneration following systemic LPS administration. Glia 61: 855-868, 2013. 
26. Li Y, Chi G, Shen B, Tian Y and Feng H: Isorhamnetin ameliorates LPS-induced inflammatory response through downregulation of NF- $\kappa$ B signaling. Inflammation 39: 1291-1301, 2016.

27. Kim TH, Ku SK and Bae JS: Anti-inflammatory activities of isorhamnetin-3-O-galactoside against HMGB1-induced inflammatory responses in both HUVECs and CLP-induced septic mice. J Cell Biochem 114: 336-345, 2013.

28. Koh PO: Cerebral ischemic injury decreases $\alpha$-synuclein expression in brain tissue and glutamate-exposed HT22 cells. Lab Anim Res 33: 244-250, 2017.

29. Park YS, Kwon YJ and Chun YJ: CYP1B1 Activates Wnt/ $\beta$-catenin signaling through suppression of Herc5-mediated ISGylation for protein degradation on $\beta$-catenin in HeLa cells. Toxicol Res 33: 211-218, 20178, 2017.

30. Lee IA, Hyam SR, Jang SE, Han MJ and Kim DH: Ginsenoside Re ameliorates inflammation by inhibiting the binding of lipopolysaccharide to TLR4 on macrophages. J Agric Food Chem 60: 9595-9602, 2012.

31. You S, Nakanishi E, Kuwata H, Chen J, Nakasone Y, He X, He J, Liu X, Zhang S, Zhang B, et al: Inhibitory effects and molecular mechanisms of garlic organosulfur compounds on the production of inflammatory mediators. Mol Nutr Food Res 57: 2049-2060, 2013.

32. Garcia G, Nanni S, Figueira I, Ivanov I, McDougall GJ, Stewart D, Ferreira RB, Pinto P, Silva RF, Brites D, et al: Bioaccessible (poly)phenol metabolites from raspberry protect neural cells from oxidative stress and attenuate microglia activation. Food Chem 215: 274-283, 2017.

33. Fetisova E, Chernyak B, Korshunova G, Muntyan M and Skulachev V: Mitochondria-targeted antioxidants as a prospective therapeutic strategy for multiple sclerosis. Curr Med Chem 24: 2086-2114, 2017

34. von Leden RE, Yauger YJ, Khayrullina G and Byrnes KR Central nervous system injury and nicotinamide adenine dinucleotide phosphate oxidase: Oxidative stress and therapeutic targets. J Neurotrauma 34: 755-764, 2017.

35. Ohl K, Tenbrock K and Kipp M: Oxidative stress in multiple sclerosis: Central and peripheral mode of action. Exp Neurol 277: $58-67,2016$.
36. Kim YE, Hwang CJ, Lee HP, Kim CS, Son DJ, Ham YW, Hellström M, Han SB, Kim HS, Park EK, et al: Inhibitory effect of punicalagin on lipopolysaccharide-induced neuroinflammation, oxidative stress and memory impairment via inhibition of nuclear factor-kappaB. Neuropharmacology 117: 21-32, 2017.

37. Iizumi T, Takahashi S, Mashima K, Minami K, Izawa Y, Abe T, Hishiki T, Suematsu M, Kajimura M and Suzuki N: A possible role of microglia-derived nitric oxide by lipopolysaccharide in activation of astroglial pentose-phosphate pathway via the Keap1/Nrf2 system. J Neuroinflammation 13: 99, 2016.

38. Slusarczyk J, Trojan E, Glombik K, Piotrowska A, Budziszewska B, Kubera M, Popiolek-Barczyk K, Lason W, Mika J and Basta-Kaim A: Anti-inflammatory properties of tianeptine on lipopolysaccharide-induced changes in microglial cells involve toll-like receptor-related pathways. J Neurochem 136: 958-970, 2016.

39. Wang X, Wang C, Wang J, Zhao S, Zhang K, Wang J, Zhang W, Wu C and Yang J: Pseudoginsenoside-F11 (PF11) exerts anti-neuroinflammatory effects on LPS-activated microglial cells by inhibiting TLR4-mediated TAK1/IKK/NF- $\kappa \mathrm{B}, \mathrm{MAPKs}$ and Akt signaling pathways. Neuropharmacology 79: 642-656, 2014.

40. Zeng KW, Zhao MB, Ma ZZ, Jiang Y and Tu PF: Protosappanin A inhibits oxidative and nitrative stress via interfering the interaction of transmembrane protein CD14 with Toll-like receptor- 4 in lipopolysaccharide-induced BV-2 microglia. Int Immunopharmacol 14: 558-569, 2012.

41. Wang X and Zhong W: Isorhamnetin attenuates collagen-induced arthritis via modulating cytokines and oxidative stress in mice. Int J Clin Exp Med 8: 16536-16542, 2015.

42. Dong GZ, Lee JH, Ki SH, Yang JH, Cho IJ, Kang SH, Zhao RJ, Kim SC and Kim YW: AMPK activation by isorhamnetin protects hepatocytes against oxidative stress and mitochondrial dysfunction. Eur J Pharmacol 740: 634-640, 2014.

This work is licensed under a Creative Commons Attribution-NonCommercial-NoDerivatives 4.0 International (CC BY-NC-ND 4.0) License. 